\title{
Optimal design of plate-and-frame heat exchangers for efficient heat recovery in process industries
}

\author{
Olga P. Arsenyeva ${ }^{\mathrm{b}, *}$, Leonid L. Tovazhnyansky ${ }^{\mathrm{a}}$, Petro O. Kapustenko ${ }^{\mathrm{a}}$, Gennadiy L. Khavin ${ }^{\mathrm{b}}$ \\ a National Technical University "Kharkiv Polytechnic Institute", 21 Frunze Str., 61002 Kharkiv, Ukraine ${ }^{1}$ \\ ${ }^{\mathrm{b}}$ AO SODRUGESTVO-T, Krasnoznamenny per. 2, off. 19, Kharkiv 61002, Ukraine ${ }^{2}$
}

\section{A R T I C L E I N F O}

\section{Article history:}

Received 15 January 2011

Received in revised form

9 March 2011

Accepted 10 March 2011

Available online 20 April 2011

\section{Keywords:}

Plate heat exchanger

Design

Mathematical model

Model parameters

\begin{abstract}
A B S T R A C T
The developments in design theory of plate heat exchangers, as a tool to increase heat recovery and efficiency of energy usage, are discussed. The optimal design of a multi-pass plate-and-frame heat exchanger with mixed grouping of plates is considered. The optimizing variables include the number of passes for both streams, the numbers of plates with different corrugation geometries in each pass, and the plate type and size. To estimate the value of the objective function in a space of optimizing variables the mathematical model of a plate heat exchanger is developed. To account for the multi-pass arrangement, the heat exchanger is presented as a number of plate packs with co- and counter-current directions of streams, for which the system of algebraic equations in matrix form is readily obtainable. To account for the thermal and hydraulic performance of channels between plates with different geometrical forms of corrugations, the exponents and coefficients in formulas to calculate the heat transfer coefficients and friction factors are used as model parameters. These parameters are reported for a number of industrially manufactured plates. The described approach is implemented in software for plate heat exchangers calculation.
\end{abstract}

(c) 2011 Elsevier Ltd. All rights reserved.

\section{Introduction}

Efficient heat recuperation is the cornerstone in resolving the problem of efficient energy usage and consequent reduction of fuel consumption and greenhouse gas emissions. New challenges arise when integrating renewables, polygeneration and CHP units with traditional sources of heat in industry and the communal sector, as it is shown by Klemeš et al. [1] and Perry et al. [2]. There is a requirement to consider minimal temperature differences in heat exchangers of reasonable size, see Fodor et al. [3]. Such conditions can be satisfied by a plate heat exchanger (PHE). Its application not only as a separate item of equipment, but as an elements of a heat recuperation systems gives even more efficient solutions, as shown by Kapustenko et al. [4]. However, the efficient use of PHEs in complex recuperation systems and heat exchanger networks demand reliable methods for their rating and sizing. This is not only required when ordering the equipment, when proprietary software of PHE manufacturers is used, but also at the design stage by the process engineer.

\footnotetext{
* Corresponding author. Tel.: +380577202278; fax: +380577202223 E-mail address: arsenyev@kpi.kharkov.ua (O.P. Arsenyeva).

1 kap@kpi.kharkov.ua.

2 sodrut@gmail.com.
}

Plate heat exchangers (PHEs) are one of the most efficient types of heat transfer equipment. The principles of their construction and design methods are sufficiently well described elsewhere, see e.g. Hesselgreaves [5], Wang, Sunden and Manglik [6], Shah and Seculić [7], Tovazshnyansky et al. [8]. This type of equipment is much more compact and requires much less material for heat transfer surface production, and a much smaller footprint, than conventional shell and tubes units. PHEs have a number of advantages over shell and tube heat exchangers, such as compactness, low total cost, less fouling, flexibility in changing the heat transfer surface area, accessibility, and what is very important for energy saving, a close temperature approach - down to $1 \mathrm{~K}$. However, due to the differences in construction principles from conventional shell and tube heat exchangers, PHEs require substantially different methods of thermal and hydraulic design.

One of the inherent features of PHEs is their flexibility. The heat transfer surface area can be changed discretely with a step equal to heat transfer area of one plate. All major producers of PHEs manufacture a range of plates with different sizes, heat transfer surface areas and geometrical forms of corrugations. This enables the PHE to closely satisfy required heat loads and pressure losses of the hot and cold streams.

The thermal and hydraulic performance of a PHE with plates of certain size and type of corrugation can be varied in two ways: (a) 
by adjusting the number of passes for each of exchanging heat streams and (b) by proper selection of plate corrugation pattern. For the most common chevron-plates, it is the angle of corrugations inclination to the plate longitudinal axis. One of early attempts to find the patterns that minimize the surface area required for heat transfer was made by Focke [9]. The optimal design of a PHE by adjusting corrugation pattern on plate surface was reported by Wang and Sunden [10]. Picon-Nunez, Polley and Jantes-Jaramillo [11] presented an alternative design approach based on graphical representation, which facilitates the choice from the options calculated for the range of available plates with different geometries. They have estimated correlations for heat transfer and hydraulic resistance from available literature data. Similar estimations were also made by Mehrabian [12], who proposed a manual method for the thermal design of plate heat exchangers. Wright and Heggs [13] have shown how the operation of a two stream PHE can be approximated after the plate rearrangement has been made, using the existing PHE performance data. Their method can help when adjusting PHE, which is already in operation, for better satisfaction to required process conditions. Kanaris, Mouza and Paras [14] have estimated parameters in correlations for Nusselt and friction factor using CFD modelling of the flow in a PHE channel of special geometry. However, their results are still a long way from practical application.

Currently for most PHEs, the effect of varying plate corrugation pattern is achieved by combining chevron-plates with different corrugation inclination angle in one PHE. The design approach and advantages of such a method were shown by Marriot [15] for a one pass counter-current arrangement of PHE channels. A one pass channel arrangement in a PHE has many advantages compared to a multi-pass one, especially in view of piping and maintenance (all connections can be made on not movable frame plate from one side of PHE). But in certain conditions the required heat transfer load and pressure drops can be satisfied more efficiently by application of multi-pass arrangement of PHE's channels.

Until the 1970s, the proper adjustment of the number of passes was the only way to satisfy the required heat load and pressure drops in PHE consisting of plates of a certain type. The multi-pass arrangement enables increased flow velocities in channels and thus to achieve higher film heat transfer coefficients if allowable pressure drop permits. But, for unsymmetrical passes, the problem of diminishing effective temperature differences has arisen. Most of the authors which have proposed design methods for PHEs have used LMTD correction factors (see e.g. Cocks [16], Kumar [17], Zinger, Barmina and Taraday [18]). Initially such correction factors could be taken from handbooks on heat exchanger design. After development of methods for analysis of complicated flow arrangements (see Pignotti and Shah [19]) it became possible to develop closed-form formulas for two-fluid recuperators. Using a matrix algorithm and the chain rule, Pignotti and Tamborenea [20] developed a computer program to solve the system of linear differential equations for the numerical calculation of the thermal effectiveness of arbitrary flow arrangements in a PHE. Kandlikar and Shah [21] analyzed different flow arrangements and proposed formulas for up to four passes. These and other similar formulas can be found in books on heat exchangers thermal design, e.g. Wang, Sunden and Manglik [6], Shah and Seculić [7]. The main assumptions made on deriving such formulas are (a) constant fluids properties and overall heat transfer coefficients, (b) uniformity of fluid flow distribution between the channels in same pass and (c) sufficiently large number of plates.

Because of the increase in computational power of modern computers the difference of heat transfer coefficients between passes can be accounted for in the design by solving the system of algebraic equations, as was proposed by Tovazshnyansky et al. [22] and further developed by Arsenyeva et al. [23]. The flow maldistribution between channels was investigated among others by Rao, Kumar and Das [24], who noticed the significant effect of heat transfer coefficient variation, which was not accounted for in previous works. However, we can adhere to the conclusion made earlier by Bassiouny and Martin [25], based on analytical study of velocity and pressure distribution in both the intake and exhaust conduits of PHE, that plate heat exchanger can be designed with equal flow distribution regardless of the number of plates. The correct design of manifolds and flow distribution zones is also very important for tackling fouling problems in PHEs, as shown by Kukulka and Devgun [26]. However the design should take account of the limitations imposed by the percentage of port and manifolds pressure drops in the total pressure losses, as well as for flow velocities. Along with flow maldistribution, Heggs and Scheidat [27] have studied end-plate effect. They concluded that critical number of plates is dependent on the required accuracy of performance, for example, 19 can be recommended for an inaccuracy of only $2.5 \%$.

The comprehensive description of existing PHE design procedures was presented by Shah and Focke [28] and Shah and Wanniarachchi [29]. Their methods were described by Shah and Seculić [7] as (1) quite involved (2) missing reliable data for thermal and hydraulic performance of commercial plates (3) less rigorous methods can be used as it is easy to change the number of plates if the designed PHE does not confirm to the specification. Quite recently even more sophisticated models and methodologies for PHEs were developed, as e.g. presented in paper of Georgiadis and Machieto [30]. These models account for dynamic behaviour of PHEs and distribution of local parameters. But substantial complication of numerical procedures, as also absence of reliable data for commercial plates, makes difficult their application at designing PHE for steady state conditions.

The significant feature of PHE design is the fact that the required conditions of certain heat transfer process can be satisfied by a number of different plates. But it is achieved with different level of success in terms of material and cost for production. The plate, which is the best for certain process conditions, should be selected from the available set of plates according to some optimization criterion. Therefore, the design of optimal PHE, for given process conditions, should be made by selection of the best option from available alternative options of plates with different geometrical characteristics. To satisfy requirements of different process conditions any PHE manufacturer is producing not just one plate type, but the sets of different types of plates. To make a right selection we need the mathematical model of PHE to estimate performance of the different alternative options. It should be accurate enough and at the same time to have small number of parameters, which can be identified on a data available for commercial plates.

This paper presents a computer aided approach for PHE thermal and hydraulic design, based on evaluation of different alternative options for available set of heat transfer plates. It consists in development of mathematical model for PHE, which accounts for possibility to use plates of different corrugation geometries in one heat exchanger, as well as adjustment of streams passes to satisfy process conditions. The generalized matrix formula to account for the influence of passes arrangement on thermal performance of PHE is proposed. The procedure for identification of model parameters using available in web information is described and as example is utilized for representative set of plates produced by a leading PHE manufacturer. The sizing of PHE is formulated as the mathematical problem of finding the minimal value for implicit nonlinear discrete/continuous objective function with inequality constraints. The solution of this problem is implemented as computer software. Two case studies for different PHE applications are presented. 


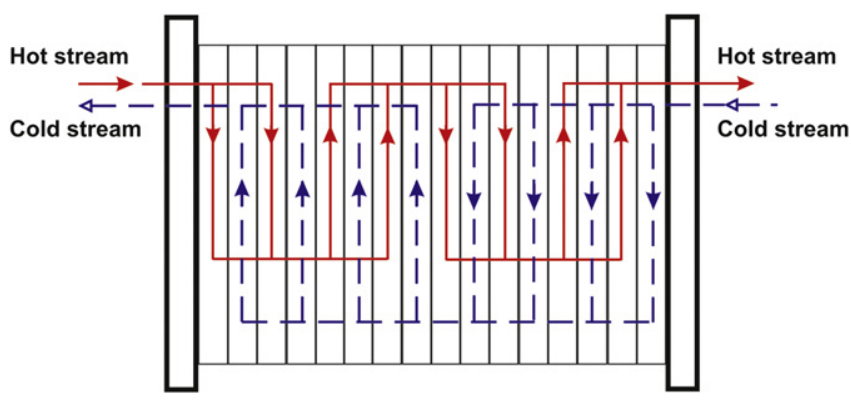

Fig. 1. An example of streams flows through channels in multi-pass PHE.

\section{Mathematical modelling of PHE}

A plate-and-frame PHE consists of a set of corrugated heat transfer plates clamped together between fixed and moving frame plates and tightened by tightening bolts. The plates are equipped with the system of sealing gaskets, which also separate the streams and organizing their distribution over the inter-plate channels. In multi-pass PHE, the plates are arranged in such a way that they form groups of parallel channels. An example is shown in Fig. 1. The temperature distribution in passes can vary and in different groups of channels both counter-current and co-current flows may occur.

The mathematical model of a PHE can be derived based on the following assumptions:

- The heat transfer process is stationary;

- No change of phases in streams;

- The number of heat transfer plates is big enough not to consider the differences in heat transfer conditions for plates at the edges of passes and of total PHE;

- Flow misdistribution in collectors can be neglected;

- The streams are completely mixed in joint parts of PHE collectors.

With these assumptions PHE can be regarded as a system of one pass blocks of plates. The conditions for all channels in such block are equal. For example, an arrangement with three passes for the hot stream $\left(X_{1}=3\right)$ and two for the cold stream $\left(X_{2}=2\right)$ is shown in Fig. 2. The heat transfer area of the block is given by $F_{b}=F /\left(X_{1} X_{2}\right)$, where $F$ is the total heat transfer area of PHE. The change of hot stream temperature in each block is $\delta t_{i}, i=1,2 \ldots 6$.

The total number of blocks is $n_{b}=\mathrm{X}_{1} \mathrm{X}_{2}$ and the number of heat transfer units in one block, counted for hot stream is:

$N T U_{b}=U_{b} \cdot F_{b} \cdot X_{2} /\left(G_{1} \cdot c_{1}\right)$

Where $U_{b}$ - overall heat transfer coefficient in block, $\mathrm{W} /\left(\mathrm{m}^{2} \mathrm{~K}\right)$; $G_{1}$ - mass flow rate of hot stream, $\mathrm{kg} / \mathrm{s} ; c_{1}$ - specific heat of hot stream, $\mathrm{J} /(\mathrm{kg} \mathrm{K})$.

If we assume $G_{1} \times c_{1} / X_{2}<G_{2} \times c_{2} / X_{1}$, then block heat exchange effectiveness $\epsilon_{b}$ for counter-current flow is:

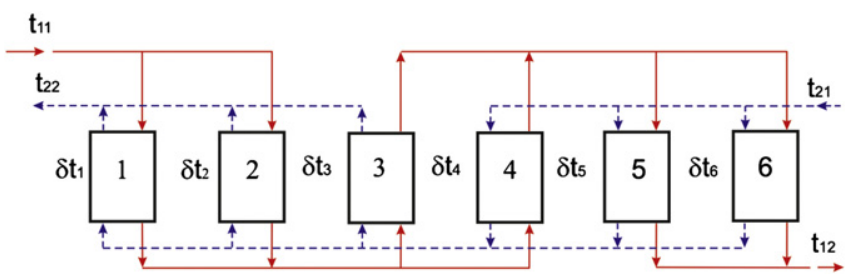

Fig. 2. The presentation of PHE as a system of plate blocks $\left(X_{1}=3, X_{2}=2\right)$. $\epsilon_{b}=\frac{1-\exp \left(N T U_{b} \cdot R_{b}-N T U_{b}\right)}{1-R_{b} \cdot \exp \left(N T U_{b} \cdot R_{b}-N T U_{b}\right)}$,

where $R_{b}=G_{1} \times c_{1} \times X_{1} /\left(G_{2} \times c_{2} \times X_{2}\right)$ - the ratio of going through block heat capacities of streams; $G_{2}$ and $c_{2}$ mass flow rate $[\mathrm{kg} / \mathrm{s}]$ and specific heat $[\mathrm{J} /(\mathrm{kg} \mathrm{K})]$ of cold stream.

If $R_{b}=1$, then $\epsilon_{b}=N T U_{b} /\left(1+N T U_{b}\right)$.

In case of co-current flow:

$\epsilon_{b}=\frac{1-\exp \left(-N T U_{b} \cdot R_{b}-N T U_{b}\right)}{1+R_{b}}$

On the other hand the heat exchange effectiveness of block $i$ is:

$\epsilon_{b i}=\delta t_{1 i} / \Delta t_{i}$

where $\delta t_{1 i}$ - temperature drop in block $i ; \Delta t_{i}$ - the temperature difference of streams entering block $i$.

The temperature change of the cold stream:

$\delta t_{2 i}=\delta t_{1 i} \cdot R_{b}$

The above relations also hold true at $G_{1} \times c_{1} / X_{2}>G_{2} \times c_{2} / X_{1}$. In that case the physical meaning of $\epsilon_{b}$ and $N T U_{b}$ are different, as shown by Shah and Seculić [7]. Thus these relations can be regarded as a mathematical model of a block, which describes the dependence of temperature changes from the characterizing block values of $F_{b}$ and $U_{b}$.

For each block we can write the equation which describes the link of temperature change in this block to the temperature changes in all other blocks of the PHE. For example, let us consider the first block in Fig. 2. The difference of temperatures for streams entering the block can be calculated by deducting the averaged temperature rise of cold stream in blocks 4,5 and 6 from the initial temperature difference $\Delta$ of the streams entering the PHE:

$\Delta t_{1}=\Delta-\left(\delta t_{4} \cdot R_{b}+\delta t_{5} \cdot R_{b}+\delta t_{6} \cdot R_{b}\right) / 3$

After substituting this into the Equation (4) and rearranging we obtain:

$\delta t_{1}+\delta t_{4} \frac{\epsilon_{b 1}}{3} R_{b}+\delta t_{5} \frac{\epsilon_{b 1}}{3} R_{b}+\delta t_{6} \frac{\epsilon_{b 1}}{3} R_{b}=\epsilon_{b 1} \Delta ;$

In this way equations can be obtained for every block in the PHE. Consequently we can obtain a system of 6 linear algebraic equations with 6 unknown variables $\delta t_{1}, \delta t_{2}, \ldots, \delta t_{6}$.

We have built these systems of equations for the number of passes up to $X_{1}=7$ and $X_{2}=6$, with an overall counter-current flow arrangement. The analysis of results have shown that, for any number of passes, the system may be presented in matrix form:

$[Z]\left[\delta t_{i}\right]=\left[\epsilon_{b i} \Delta\right]$,

where $\left[\delta t_{i}\right]$ - vector-column of temperature drops in blocks; $\left[\epsilon_{i} \Delta\right]-$ vector-column of the right hand parts of the system; [Z] - matrix of system coefficients, whose elements are:

$$
z_{i j}=\left[\begin{array}{l}
\frac{\varepsilon_{b i} R_{b}}{2 X_{1}}\left\{1 \cdot \operatorname{sign}\left(j-\left(\operatorname{int}\left[\frac{i-1}{X_{i}}\right]+1\right) X_{1}+0.5\right)+1\right\}, \text { if } j>i \\
1, \text { if } i=j \\
\frac{\epsilon_{b i}}{2 X_{2}}\left\{1 \cdot \operatorname{sign}\left(\operatorname{int}\left[\frac{i-1}{X_{2}}\right] X_{2}-j+0.5\right)+1\right\}, \text { if } j<i
\end{array}\right]
$$

Here $i$ - row number; $j$ - column number. 
The numerical solution of this type of linear algebraic Equations system (7) can be easily performed on a PC, after which the total temperatures change in the PHE can be calculated as:

$\delta t_{\Sigma 1}=\sum_{i=1}^{X_{1}}\left(\frac{1}{X_{1}} \sum_{i i=1}^{X_{2}} \delta t_{(i-1) X_{2}+i i}\right) ; \delta t_{\Sigma 2}=\frac{\left(G_{1} c_{1}\right)}{\left(G_{2} c_{2}\right)} \delta t_{\Sigma 1}$

The total heat load of PHE is:

$Q=\delta t_{\Sigma 1} \cdot G_{1} \cdot c_{1}$,

This system should be accompanied by equations for the calculation of the overall heat transfer coefficient $U, \mathrm{~W} / \mathrm{m}^{2} \mathrm{~K}$, as below.

$U=1 /\left(\frac{1}{h_{1}}+\frac{1}{h_{2}}+\left(\frac{\delta_{w}}{\lambda_{w}}\right)+R_{f}\right)$

where $h_{1}, h_{2}-$ film heat transfer coefficients for hot and cold streams, respectively, $\mathrm{W} / \mathrm{m}^{2} \mathrm{~K} ; \delta_{w}$ - the wall thickness, $\mathrm{m} ; \lambda_{w}$ - heat conductivity of the wall material, $\mathrm{W} /(\mathrm{m} \mathrm{K}) ; R_{f}=R_{f 1}+R_{f 2}-$ the sum of fouling thermal resistances for streams, $\mathrm{m}^{2} \mathrm{~K} / \mathrm{W}$.

For plate heat exchangers the film heat transfer coefficients are usually calculated by empirical correlations:

$N u=f(\operatorname{Re}, \operatorname{Pr})=A \cdot \operatorname{Re}^{n} \operatorname{Pr}^{0.4}\left(\mu / \mu_{w}\right)^{0.14}$

where $\mu$ and $\mu_{w}$ are the dynamic viscosities at stream and at wall temperatures, respectively; the Nusselt number is:

$N u=h \cdot d_{e} / \lambda$,

$\lambda$ - heat conductivity of the respective stream, $\mathrm{W} /(\mathrm{m} \mathrm{K})$; $d_{e}-$ equivalent diameter of inter-plate channel, $\mathrm{m}$.

$d_{e}=\approx \frac{4 b \delta}{2(b+\delta)} \approx 2 \delta$,

where $\delta$ - inter-plate gap, $\mathrm{m} ; b$ - channel width, $\mathrm{m}$.

The Reynolds number is given by:

$\operatorname{Re}=w \cdot d_{e} \cdot \rho / \mu$

where $w$ - stream velocity in channel, $\mathrm{m} / \mathrm{s}$.

The Prandtl number is given by:

$\operatorname{Pr}=c \cdot \mu / \lambda$,

where $\rho$ - stream density, $\mathrm{kg} / \mathrm{m}^{3} ; c$ - specific heat capacity of the stream, $\mathrm{J} /(\mathrm{kg} \mathrm{K})$. The streams velocities are calculated as:

$w=g /(f \cdot \rho)$

Where $g$ is the flow rate of the stream through one channel, $\mathrm{kg} / \mathrm{s}$; $f$ - cross section area of inter-plate channel, $\mathrm{m}^{2}$.

The pressure drop in one PHE channel is given by:

$\Delta p=\zeta \cdot \frac{L_{p}}{d_{e}} \cdot \frac{\rho \cdot w^{2}}{2}+\Delta p_{p-c}$,

where $\Delta p_{p-c}=1.3 \times \rho \times w_{\text {port }}^{2} / 2$ - pressure losses in ports and collector part; $L_{p}$ - effective plate length, $\mathrm{m} ; w_{\text {port }}$ - velocity in PHE ports and collectors; $\zeta$ - friction factor, which is usually determined by empirical correlations of following form:

$\zeta=B / \operatorname{Re}^{m}$

For multi-pass PHE the pressure drop in one pass is multiplied by the number of passes $X$.

In modern PHEs plates of one type are usually made with two different corrugation angles, which can form three different channels, when assembled in PHE, as shown in Fig. 3.
$\mathrm{H}$ type plates have corrugations with larger angles (about $60^{\circ}$ ) which form the $\mathrm{H}$ channels with higher intensity of heat transfer and larger hydraulic resistance. L type plates have a lower angle (about $30^{\circ}$ ) and form the $\mathrm{L}$ channels which have lower heat transfer and smaller hydraulic resistance. Combined, these plates form M channels with intermediate characteristics (see Fig. 3). This design technique allows the thermal and hydraulic performance of a plates pack to be changed with a level of discreteness equal to one plate in a pack.

In one PHE two groups of channels are usually used. One is of higher hydraulic resistance and heat transfer ( $x$-channel), another of lower characteristics ( $y$-channel). When the stream is flowing through a set of these channels, the temperature changes in the different channels differ. After mixing in the collector part of the PHE block, the temperature is determined by the heat balance. The heat exchange effectiveness of the plates block with different channels is given by:

$\epsilon_{b}=\left(g_{x} \cdot n_{x} \cdot \epsilon_{x}+g_{y} \cdot n_{y} \cdot \epsilon_{y}\right) /\left(g_{x} \cdot n_{x}+g_{y} \cdot n_{y}\right)$,

where $n_{x}$ and $n_{y}$ are the numbers of $x$ - and $y$-channels in a block of plates, respectively; $g_{x, y}=w_{x, y} \times \rho \times f_{c h}$ - the mass flow rates through one channel of type $x$ or $y$. These flow rates should satisfy the equation $\Delta p_{x}=\Delta p_{y}$ and the material balance:

$g_{x} \cdot n_{x}+g_{y} \cdot n_{y}=G_{b}$,

where $G_{b}$ - flow rate of the stream through the block of plates.

The principle of plate mixing in one heat exchanger gives the best results with symmetrical arrangement of passes $\left(X_{1}=X_{2}\right)$ and $G_{b}$ equal to the total flow rate of the respective stream. The unsymmetrical arrangement $X_{1} \neq X_{2}$ is usually used when all channels are the same (any of the three available types).

When the numbers of channels are determined, the numbers of plates can be calculated by:

$N_{p l}=\sum_{i=1}^{X_{1}}\left(n_{x 1 i}+n_{y 1 i}\right)+\sum_{j=1}^{X_{2}}\left(n_{x 2 i}+n_{y 2 i}\right)+1$

The total heat transfer area of the PHE (with two end plates not included) is given by:

$F_{\mathrm{PHE}}=\left(N_{p l}-2\right) \cdot F_{p l}$,

where $F_{p l}$ - heat transfer area of one plate, $\mathrm{m}^{2}$.

The above algebraic Equations (1)-(23) describe the relationship between variables which characterize a PHE and the heat transfer process contained within the PHE. These equations can be presented as a mathematical model of a PHE, and the solution allows the calculation of the pressure and temperature change of streams entering the heat exchanger. It is a problem of PHE rating (analysis) .

\section{Optimization of PHE}

The problem of PHE sizing (synthesis) requires finding characteristics such as plate type, the numbers of passes, and the number

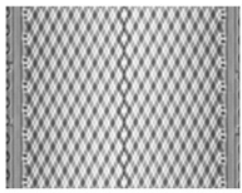

a

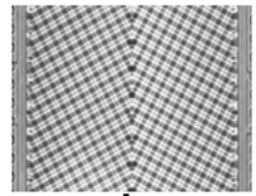

b

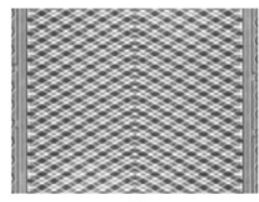

C
Fig. 3. Channels formed by combining plates of different corrugation geometries: a) Channel L formed by L-plates; b) Channel M formed by L- and H-plates; c) Channel $\mathrm{H}$ formed by H-plates. 
of plates with different corrugations, which will best satisfy to the required process conditions. Here the optimal design with pressure drop specification is considered, as originally described by Wang and Sunden [10].

The most important and costly parts of plate-and-frame PHE are plates with gaskets. The plates can be made of stainless steels, titanium and other even more expensive alloys and metals. All other component parts of PHE (frame plates, bars, tightening bolts, etc.) usually are made from less expensive construction steels and have a smaller share in a cost of PHE. The plates constitute the heat transfer area of PHE and there is strong dependence between the cost of PHE and its heat transfer area. Therefore, for optimization of PHE heat transfer area $F$ can be taken as objective function, which is also characterizing the PHE cost and the need in sophisticated materials for plates and gaskets.

For specific process conditions, when temperatures and flow rates of both streams are specified, required heat transfer surface area $F_{\mathrm{PHE}}$ is determined through solution of mathematical model presented in previous chapter by Equations (1)-(23). It is implicit function of plate type $T_{p l}$, number of passes $X_{1}, X_{2}$, and composition of plates with different corrugations pattern $\left[N_{H} / N_{L}\right]$. We can formulate the optimization problem for PHE design as a task to find the minimum of the following objective function:

$F_{P H E}=f\left(T_{p l}, X_{1}, X_{2},\left[N_{H} / N_{L}\right]\right)$

It should satisfy to constraints imposed by required process conditions:

Heat load $Q$ must be not less than required $Q^{0}$ :

$Q \geq Q^{0}$ or $\Delta t_{1} \geq \Delta t_{1}^{0}$

The pressure drops of both streams must not exceed allowable:

$\Delta p_{1} \leq \Delta p_{1}^{0}$

$\Delta p_{2} \leq \Delta p_{2}^{0}$

There are also constraints imposed by the features of PHE construction.

On a flow velocity in ports:

$w_{\text {port }} \leq 7 \mathrm{~m} / \mathrm{s}$

The share of pressure losses in ports and collector $\Delta p_{p-c}$ in total pressure drop for both streams:

$\left(\Delta p_{p-c} / \Delta p\right)_{1,2} \leq 0.3$

The number of plates on one frame must not exceed the maximum allowable for specific type of PHE plates $n_{\max }\left(T_{p l}\right)$ :

$N_{H}+N_{L} \leq n_{\max }\left(T_{p l}\right)$

In the PHE the numbers of channels and their form for both sides must be the same, or differ only on 1 channel:

$\operatorname{abs}\left[\sum_{i=1}^{X_{1}} n_{x 1 i}-\sum_{j=1}^{X_{2}} n_{x 2 i}\right] \leq 1$

$\operatorname{abs}\left[\sum_{i=1}^{X_{1}} n_{y 1 i}-\sum_{j=1}^{X_{2}} n_{y 2 i}\right] \leq 1$

Analysis of the relations described in Equations (1)-(32) show that we have a mathematical problem of finding the minimal value for implicit nonlinear discrete/continues objective function with inequality constraints. It does not permit analytical solution without considerable simplifications, but can be readily solved on modern computers numerically. The basis of the developed algorithm is the fact that optimal solution must be situated in the vicinity of the border, by which constraints on the pressure drop in PHE are limiting the space of possible solutions. Usually in one PHE three possible types of channel can be used. For limiting flow rates of $i$-th stream in one channel of the $j$-type from constraints on pressure drop (26) and (27), using Equations (17)-(19), we get:

$g_{i j}^{0}=\left[\frac{2 \cdot\left(\Delta p_{i}^{0}-0,65 \cdot X_{i} \cdot \rho_{i} \cdot w_{\text {port }}^{2}\right) \cdot d_{e q} \cdot \rho_{i} \cdot f_{j}^{2}}{L_{p} \cdot B_{j} \cdot X_{i}}\left(\frac{d_{e}}{f_{j} \cdot \rho_{i} \cdot \nu_{i}}\right)^{m_{j}}\right]^{\frac{1}{2-m_{j}}}$

Due to constraints (31) and (32) the required pressure drops for both streams cannot be exactly satisfied simultaneously. We should correct the flow rates for one of the streams, using constraints (31) and (32) with assumptions that they are both strict inequalities and all passes have the same numbers of channels:

$G_{1} / g_{1 j}=G_{2} / g_{2 j}$

The possible difference in amount of one channel can be accounted for at rating design.

At known values of $g_{i j}$ the film and overall heat transfer coefficients and all coefficients of the system of linear algebraic equations are directly calculated by equations of the above mathematical model. The system is solved by standard utility programs. When the required $\Delta t^{0}{ }_{1}$ drops between the values of calculated $\Delta t_{1 j}$ for two channels, the required numbers of these channels and after corresponding plates of different corrugations are calculated using Equations (20)-(22). In case of $\Delta t^{0}{ }_{1}$ lower than the smallest $\Delta t_{1 j}$ all L-plates are used and constraint (25) is satisfied as inequality. Margin on heat transfer load can be calculated:

$M_{Q}=\Delta t_{1 L} / \Delta t_{1}^{0}-1=Q / Q^{0}-1$

If $\Delta t_{1}{ }^{0}$ higher than the biggest $\Delta t_{1 j}$, all $\mathrm{H}$-plates are taken and their number increased until the constraint (25) is satisfied. But in this case appears the big margin on constraints (26) and (27). Allowable pressure drops are not completely utilized and configurations with the increased passes numbers must be checked.

The calculations are starting from $X_{1}=1$ and $X_{2}=1$. The number of passes is increased until the calculated heat transfer surface area is lowered. If the area increases, the calculations terminated, all derived surface areas compared, and the option with smallest area selected. The procedure can be applied to all available for design plate types. After the best option is selected, nearby options are also available for designer decision.

The algorithm outlined above is inevitably leading to the best solution for any number $N_{T}$ of available plate types $T_{p l}$. It is implemented in developed software for IBM compatible PC. However, the mathematical model contains some parameters, namely coefficients and exponents in empirical correlations, which are not readily available.

\section{Identification of mathematical model parameters}

\subsection{Procedure of numerical experiment}

As a rule the empirical correlations for design of industrially manufactured PHEs are obtained during tests on such heat 
exchangers at specially developed test rigs. Such tests are made for every type of new developed plates and inter-plate channels. The results are proprietary of manufacturing company and not usually published.

Based on the above mathematical model, a numerical experimental technique has been developed which enables the identification of the model parameters by comparison with results obtained for the same conditions with the use of PHE calculation software, which is now available on the Internet from most PHE manufacturers.

The computer programs for thermal and hydraulic design of PHEs in result of calculations give the information about following parameters of designed heat exchanger: $Q$ - heat load, $W ; t_{11}, t_{12}-$ hot stream inlet and outlet temperatures, ${ }^{\circ} \mathrm{C} ; t_{21}, t_{22}$ - cold stream inlet and outlet temperatures, ${ }^{\circ} \mathrm{C} ; G_{1}, G_{2}$ - flow rates of hot and cold streams, $\mathrm{kg} / \mathrm{s} ; \Delta P_{1}, \Delta P_{2}$ - pressure losses of respective streams, Pa; $n_{1}, n_{2}$ - numbers of channels for streams; $N_{p l}$ - number of heat transfer plates and heat transfer area $F, \mathrm{~m}^{2}$. One set of such data can be regarded as a result of experiment with calculated PHE. The overall heat transfer coefficient $U, \mathrm{~W} /\left(\mathrm{m}^{2} \mathrm{~K}\right)$, even if not presented, can be easily calculated on these data, as also the thermal and physical properties of streams.

The PHE thermal design is based on empirical correlations (12). When all plates in PHE have the same corrugation pattern, the formulas for heat transfer coefficients are the same for both streams and can be written in following form:

$\frac{h_{1,2} d_{e}}{\lambda_{1,2}}=A \cdot\left(\frac{G_{1,2} d_{e}}{f \cdot \mu_{1,2} \cdot N_{1,2}}\right)^{n} \cdot\left(\frac{c_{1,2} \mu_{1,2}}{\lambda_{1,2}}\right)^{0.4} \cdot\left(\frac{\mu_{1,2}}{\mu_{w}}\right)^{0.14}$

In one pass PHE with equal numbers of channels $\left(N_{1}=N_{2}\right)$ for both streams the ratio of the film heat transfer coefficients is:

$a=\frac{h_{1}}{h_{2}}=\left(\frac{G_{1}}{G_{2}}\right)^{n} \cdot\left(\frac{\lambda_{1}}{\lambda_{2}}\right)^{0.6} \cdot\left(\frac{\mu_{2}}{\mu_{1}}\right)^{n-0.54} \cdot\left(\frac{c_{1}}{c_{2}}\right)^{0.4} \cdot\left(\frac{\mu_{w}}{\mu_{w}}\right)^{0.14}$

The overall heat transfer coefficient for clean surface conditions is determined by Equation (11) with $R_{f}=0$. When fluids of both streams are same and they have close temperatures, we can take $\mu_{w 1}=\mu_{w 2}$. Assuming initial value for $n=0.7$, from the last two equations the film heat transfer coefficient for hot stream:

$h_{1}=\frac{1+a}{\frac{1}{U}-\frac{\delta_{w}}{\lambda_{w}}}$

For the cold stream

$h_{2}=h_{1} / a$

In case of equal flow rates $\left(G_{1}=G_{2}\right)$ the plate surface temperature at hot side:

$t_{w 1}=\frac{t_{11}+t_{12}}{2}-\frac{Q}{F \cdot h_{1}}$

At cold side

$t_{w 2}=\frac{t_{21}+t_{22}}{2}+\frac{Q}{F \cdot h_{2}}$

At these temperatures the dynamic viscosity coefficients $\mu_{w 1}, \mu_{w 2}$ are determined.

By determined values of film heat transfer coefficients we calculate Nusselt numbers for hot and cold streams (12) and the dimensionless parameters
$K_{1,2}=\frac{N u_{1,2}}{\operatorname{Pr}_{1,2}^{0.4} \cdot\left(\mu_{1,2} / \mu_{w 1,2}\right)^{0.14}}$

Making calculations of the same PHE for different flow rates, which ensure the desired range of Reynolds numbers, we obtain the relationship

$K=\Phi(\operatorname{Re})$

Plotted in logarithmic coordinates it enables to estimate parameters $A$ and $n$ in correlation (12). To determine these parameters Least Squares method can be used. If the value of $n$ much different from initially assumed 0.7 , the film heat transfer coefficients recalculated and new relationship (43) obtained. The corrected values of $A$ and $n$ can be regarded as final solution.

The pressure drop in PHE is determined by Equation (18) with friction factor determined by Equation (19).

Using these equations the values of friction factors for hot and cold streams can be obtained from the same data of PHE numerical experiments for calculation of heat transfer coefficients, using data on pressure drops $\Delta p_{1}$ and $\Delta p_{2}$. It gives the relation between friction factor and Reynolds number. From this relation parameters $A$ and $m$ are easily obtained using List Squares method.

To obtain the representative data the numerical experiments must satisfy the following conditions.

1. The calculations are made in "rating" or "performance" mode for equal flow rates of hot and cold streams. In case of "rating" the outlet temperatures should be adjusted to have margin equal to zero.

2. The PHE is having one type of inter-plate channels - L (low duty), $\mathrm{H}$ (high duty) or $\mathrm{M}$ (medium duty). These channels are formed by L-plates, $\mathrm{H}$-plates or $\mathrm{M}$-mixture of $\mathrm{L}$ and $\mathrm{H}$ plates.

3. To eliminate end-plate effect the number of plates in PHE should be more than 21 .

4. All numerical experiments made for water as both streams. The inlet temperature of hot stream $50{ }^{\circ} \mathrm{C}$. The inlet temperature of cold stream in the range of $30-40{ }^{\circ} \mathrm{C}$.

\subsection{Example of parameters identification}

To illustrate the above procedure we performed three sets of numerical experiments for Alfa Laval plate M-10B (see [31]) with the use of computer program CAS-200 (see e.g. [32]). The calculations are made for PHE with total 31plates for three plate arrangements: 1) H-plates only; 2) L-plates only; 3) M-the mixture of $15 \mathrm{~L}$-plates and $16 \mathrm{H}$-plates. The hot water inlet temperature is $50{ }^{\circ} \mathrm{C}$. Cold water comes with temperature $40^{\circ} \mathrm{C}$. The geometrical parameters of plates and inter-plate channels are given at Table 1. These parameters are estimated from information available at CAS200 and also by measurements on the samples of real plates. The results for heat transfer calculations according to described above procedure are presented on Fig. 4 . The obtained sets of parameters in correlation (12) permit to calculate heat transfer coefficients with mean square error $1.3 \%$ and maximum deviation $\pm 3.5 \%$. The values of these parameters are presented in Table 2 .

The friction factor data are presented on Fig. 5. The change of lines slopes is obvious. The obtained parameters of correlation (19) are given at Table 2 . The mean square error of this correlation fitting the data is $1.5 \%$ and maximum deviation $\pm 3.8 \%$.

The geometrical characteristics and parameters obtained in the same manner for four other types of plates are presented in Tables 1 and 2 (for description of PHEs with these plate types see Ref. [31]). They can be used for statistics when generalizing the correlations for PHEs thermal and hydraulic performance, for modelling of PHEs 
Table 1

Estimations for geometrical parameters of some Alfa Laval PHE plates.

\begin{tabular}{llllllll}
\hline $\begin{array}{c}\text { Plate } \\
\text { type }\end{array}$ & $\delta, \mathrm{mm}$ & $d_{e}, \mathrm{~mm}$ & $\begin{array}{l}b, \\
\mathrm{~mm}\end{array}$ & $\begin{array}{l}F_{p l}, \\
\mathrm{~m}^{2}\end{array}$ & $\begin{array}{l}D_{\text {connection, }} \mathrm{mm} \\
\text { m }\end{array}$ & $f_{\text {ch }} \times 10^{3}, \mathrm{~m}^{2}$ & $L_{p}, \mathrm{~mm}$ \\
\hline M3 & 2.4 & 4.8 & 100 & 0.032 & 36 & 0.240 & 320 \\
M6 & 2.0 & 4.0 & 216 & 0.15 & 50 & 0.432 & 694 \\
M6M & 3.0 & 6.0 & 210 & 0.14 & 50 & 0.630 & 666 \\
M10B & 2.5 & 5.0 & 334 & 0.24 & 100 & 0.835 & 719 \\
M15B & 2.5 & 5.0 & 449 & 0.62 & 150 & 1.123 & 1381 \\
\hline
\end{tabular}

when making multiple calculations for heat exchangers network design and also for education of engineers specializing on heat transfer equipment selection.

\subsection{Error analysis}

The error estimation have shown that the obtained sets of parameters, which are presented in Table 2, permit to calculate heat transfer coefficients and friction factors with mean square error $1.5 \%$ and maximum deviation not more than $\pm 4 \%$. The error for calculation of heat transfer area not more than $4 \%$.

The correlations and developed software can be used only for preliminary calculations, when optimizing PHEs or heat exchanger network. The final calculations when ordering the PHE should be made by its manufacturer.

\section{Case studies}

To illustrate the influence of passes, plate type and plates arrangement on PHE performance we can consider two case studies. The first is for a PHE which has been designed to work in a distillery plant. The second is taken from paper of Wang and Sunden [10]. The calculations are made with the developed software. Two more examples of calculations with this software are presented in paper [33].

\subsection{Case study 1}

Example 1a. It is required to heat $5 \mathrm{~m}^{3} / \mathrm{h}$ of distillery wash fluid from 28 to $90.5^{\circ} \mathrm{C}$ using hot water which has a temperature of $95^{\circ} \mathrm{C}$ and a flow rate $15 \mathrm{~m}^{3} / \mathrm{h}$. The pressures of both fluids are 5 bar. The allowable pressure drops for the hot and cold streams are both

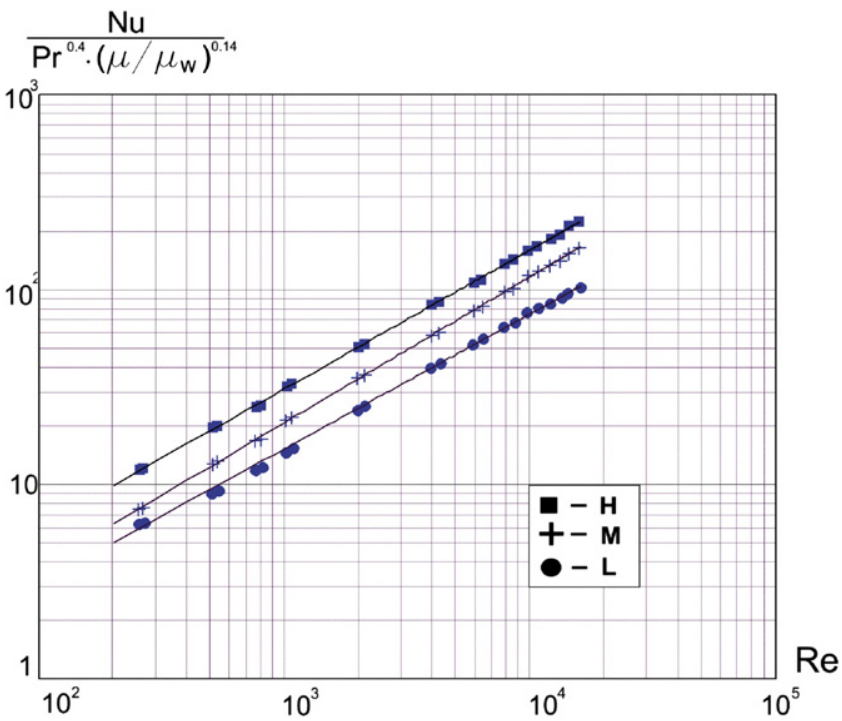

Fig. 4. Heat transfer relations for channels formed by different sets of M10B plates.
Table 2

Estimations by proposed method for parameters in correlations (12) and (19) for some Alfa Laval PHEs $(20,000>\operatorname{Re}>250,12>\operatorname{Pr}>1)$

\begin{tabular}{|c|c|c|c|c|c|c|}
\hline Plate type & Channel type & A & $\mathrm{n}$ & $\operatorname{Re}$ & B & $\mathrm{m}$ \\
\hline \multirow[t]{6}{*}{ M3 } & \multirow[t]{2}{*}{$\mathrm{H}$} & \multirow[t]{2}{*}{0.265} & \multirow[t]{2}{*}{0.7} & $<520$ & 33 & 0.25 \\
\hline & & & & $\geq 520$ & 10.7 & 0.07 \\
\hline & \multirow[t]{2}{*}{$\mathrm{L}$} & \multirow[t]{2}{*}{0.12} & \multirow[t]{2}{*}{0.7} & $<1000$ & 18.8 & 0.33 \\
\hline & & & & $\geq 1000$ & 8.8 & 0.22 \\
\hline & \multirow{2}{*}{$\mathrm{M}$} & \multirow{2}{*}{0.18} & \multirow[t]{2}{*}{0.7} & $<1000$ & 44 & 0.4 \\
\hline & & & & $\geq 1000$ & 5.1 & 0.1 \\
\hline \multirow[t]{6}{*}{ M6 } & \multirow[t]{2}{*}{$\mathrm{H}$} & \multirow[t]{2}{*}{0.25} & \multirow[t]{2}{*}{0.7} & $<1250$ & 10 & 0.2 \\
\hline & & & & $\geq 1250$ & 2.4 & 0.0 \\
\hline & \multirow[t]{2}{*}{$\mathrm{L}$} & \multirow[t]{2}{*}{0.12} & \multirow[t]{2}{*}{0.7} & $<1500$ & 5.1 & 0.3 \\
\hline & & & & $\geq 1500$ & 1.7 & 0.15 \\
\hline & \multirow[t]{2}{*}{ M } & \multirow[t]{2}{*}{0.165} & \multirow[t]{2}{*}{0.7} & $<930$ & 9.3 & 0.3 \\
\hline & & & & $\geq 930$ & 2.72 & 0.12 \\
\hline \multirow[t]{6}{*}{ M6M } & \multirow[t]{2}{*}{$\mathrm{H}$} & \multirow[t]{2}{*}{0.27} & \multirow[t]{2}{*}{0.7} & $<1300$ & 11.7 & 0.13 \\
\hline & & & & $\geq 1300$ & 4.55 & 0.0 \\
\hline & \multirow[t]{2}{*}{$\mathrm{L}$} & \multirow[t]{2}{*}{0.11} & \multirow[t]{2}{*}{0.71} & $<2200$ & 4.23 & 0.23 \\
\hline & & & & $\geq 2200$ & 1.88 & 0.12 \\
\hline & \multirow[t]{2}{*}{ M } & \multirow[t]{2}{*}{0.14} & \multirow[t]{2}{*}{0.73} & $<2100$ & 5.61 & 0.16 \\
\hline & & & & $\geq 2100$ & 1.41 & 0.0 \\
\hline \multirow[t]{6}{*}{ M10B } & $\mathrm{H}$ & 0.224 & 0.713 & $<2100$ & 12.7 & 0.17 \\
\hline & & & & $\geq 2000$ & 3.53 & 0.0 \\
\hline & $\mathrm{L}$ & 0.126 & 0.693 & $<1600$ & 9.18 & 0.32 \\
\hline & & & & $\geq 1500$ & 2.43 & 0.14 \\
\hline & M & 0.117 & 0.748 & $<2150$ & 6.56 & 0.2 \\
\hline & & & & $\geq 2150$ & 2.09 & 0.05 \\
\hline M15B & $\mathrm{H}$ & 0.26 & 0.7 & & 5.84 & 0.05 \\
\hline & $\mathrm{L}$ & 0.085 & 0.74 & $<2900$ & 5.2 & 0.28 \\
\hline & & & & $\geq 2900$ & 1.57 & 0.13 \\
\hline & M & 0.13 & 0.74 & $<3500$ & 4.3 & 0.15 \\
\hline & & & & $\geq 3500$ & 1.25 & 0.0 \\
\hline
\end{tabular}

1.0 bar. The properties of the wash fluid are considered constant and are as follows: density $-978.4 \mathrm{~kg} / \mathrm{m}^{3}$; heat capacity $-3.18 \mathrm{~kJ} /$ ( $\mathrm{kg} \mathrm{K})$; conductivity $-0.66 \mathrm{~W} /(\mathrm{m} \mathrm{K})$. Dynamic viscosity at temperatures $t=25 ; 60 ; 90{ }^{\circ} \mathrm{C}$ is taken as $\mu=19.5 ; 16.6 ; 9.0 \mathrm{cP}$.

The optimal solution is obtained for plate type M6M with spacing of plates $\delta=3 \mathrm{~mm}$ (see Table 1 ). The results of calculations for different passes numbers $X_{1}$ and $X_{2}$ and optimal for those passes plates arrangements are presented in Table 3 . The corresponding total numbers of plates in PHE are shown on diagram in Fig. 6. The vertical bars on the diagram represent the minimal numbers of plates, which are required to satisfy process conditions in PHE with specified passes arrangement. These numbers of plates correspond to local optimums achieved when passes numbers are constrained to certain exact values. The smallest is 38 plates. It corresponds to minimal value of objective function $F_{\mathrm{PHE}}=5.04 \mathrm{~m}^{2}$, which is

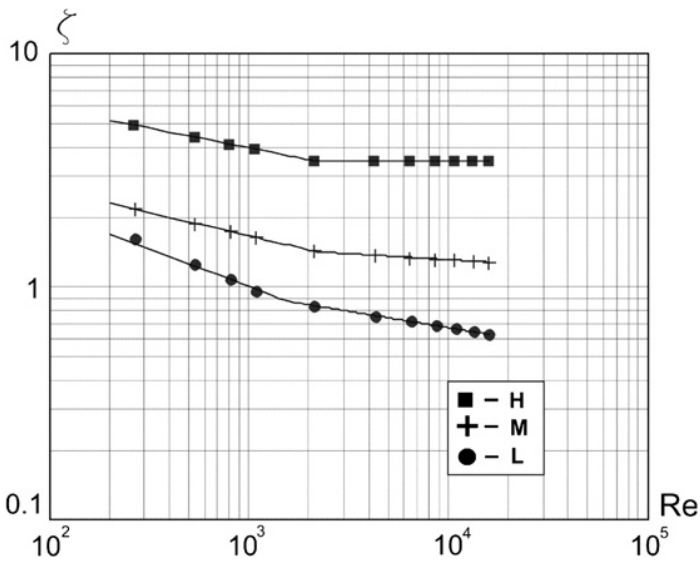

Fig. 5. Friction factor data for channels formed by M10B plates. 
Table 3

The influence of passes numbers and plate arrangement on heat transfer area in M6M PHE for conditions of Example 1a.

\begin{tabular}{|c|c|c|c|c|}
\hline \multirow[t]{2}{*}{$X_{2}$} & \multicolumn{4}{|l|}{$X_{1}$} \\
\hline & 1 & 2 & 3 & 4 \\
\hline \multirow[t]{2}{*}{1} & $7.56 \mathrm{~m}^{2}$ & $32.34 \mathrm{~m}^{2}$ & $21.70 \mathrm{~m}^{2}$ & $25.48 \mathrm{~m}^{2}$ \\
\hline & $1 \times 28 \mathrm{H} / 1 \times 27 \mathrm{H}$ & $2 \times 58 \mathrm{H} / 1 \times 116 \mathrm{H}$ & $3 \times 26 \mathrm{H} / 1 \times 78 \mathrm{H}$ & $4 \times 23 \mathrm{H} / 1 \times 91 \mathrm{H}$ \\
\hline \multirow[t]{2}{*}{2} & $9.80 \mathrm{~m}^{2}$ & $6.58 \mathrm{~m}^{2}$ & $8.26 \mathrm{~m}^{2}$ & $8.68 \mathrm{~m}^{2}$ \\
\hline & $1 \times 35 \mathrm{H} / 2 \times 18 \mathrm{H}$ & $2 \times(6 \mathrm{H}+6 \times M) / 2 \times(6 \mathrm{H}+6 \times M)$ & $3 \times 10 \mathrm{M} / 2 \times 15 \mathrm{M}$ & $4 \times 8 \mathrm{~L} / 1 \times 15 \mathrm{~L}+1 \times 16 \mathrm{~L}$ \\
\hline \multirow[t]{2}{*}{3} & $5.88 \mathrm{~m}^{2}$ & $6.58 \mathrm{~m}^{2}$ & $5.74 \mathrm{~m}^{2}$ & $6.72 \mathrm{~m}^{2}$ \\
\hline & $1 \times 21 \mathrm{H} / 2 \times 7 \mathrm{H}+1 \times 8 \mathrm{H}$ & $2 \times 12 \mathrm{M} / 3 \times 8 \mathrm{M}$ & $3 \times(4 \mathrm{M}+3 \times \mathrm{L}) / 3 \times(4 \mathrm{M}+3 \times \mathrm{L})$ & $3 \times 6 \mathrm{~L}+1 \times 7 \mathrm{~L} / 3 \times 8 \mathrm{~L}$ \\
\hline \multirow[t]{2}{*}{4} & $8.54 \mathrm{~m}^{2}$ & $5.04 \mathrm{~m}^{2}$ & $6.44 \mathrm{~m}^{2}$ & $6.72 \mathrm{~m}^{2}$ \\
\hline & $1 \times 31 \mathrm{M} / 1 \times 7 \mathrm{M}+3 \times 8 \mathrm{M}$ & $2 \times 9 \mathrm{M} / 1 \times 4 \mathrm{M}+3 \times 5 \mathrm{M}$ & $3 \times 8 \mathrm{~L} / 1 \times 5 \mathrm{~L}+3 \times 6 \mathrm{~L}$ & $3 \times 6 \mathrm{~L}+1 \times 7 \mathrm{~L} / 4 \times 6 \mathrm{~L}$ \\
\hline
\end{tabular}

achieved at $X_{1}=2$ and $X_{2}=4$ with all medium channels ( $19 \mathrm{H}$ and 19 L plates in PHE). It is the optimum for PHE assembled with M6M plates. The numbers of plates for $X_{1}>4$ and $X_{2}>4$ are bigger than already achieved minimum of 38 plates, and are not shown on diagram. If we would have only one plate type in the PHE, the minimal number of plates would be $44\left(F_{\mathrm{PHE}}=5.88 \mathrm{~m}^{2}\right)$ for both $\mathrm{H}$ and $\mathrm{L}$ plates, that is $15 \%$ higher than with mixed channels.

The closest other option for described above conditions is the PHE with plate type M6, having smaller spacing $\delta=2 \mathrm{~mm}$ (see Table 1$)$. This PHE has $36 \mathrm{H}$-plates $\left(F_{\mathrm{PHE}}=5.1 \mathrm{~m}^{2}\right)$ with one pass channels arrangement $1 \times 17 \mathrm{H} / 1 \times 18 \mathrm{H}$. When analyzing other aspects of PHE application, such as maintenance, piping arrangement, the length of plate pack, this option can be probably chosen by the process engineer. In the next two examples we will study how the process conditions can influence an optimal solution.

Example 1b. Consider the case when wash fluid should be heated from 28 to $92.5^{\circ} \mathrm{C}$ with pressure drops of both streams not more than 0.4 bar. All other conditions are the same as in example $1 a$. The optimal solution is PHE with $47 \mathrm{M} 6$ plates $\left(F_{\mathrm{PHE}}=6.75 \mathrm{~m}^{2}\right)$ and one pass channels arrangement $1 \times 23 \mathrm{H} / 1 \times 23 \mathrm{H}$. For PHE with M6M plates the best solution is for 61 plates $\left(F_{\mathrm{PHE}}=8.26 \mathrm{~m}^{2}\right)$, there two and four passes for streams and channels arrangement $2 \times 15 \mathrm{M} /$ $(2 \times 7 \mathrm{M}+2 \times 8 \mathrm{M})$. One can see that the plate M6 much better suitable for examined conditions than M6M. The PHE with M6 plates has heat transfer area smaller on $22 \%$ and one pass channels arrangement.

Example 1c. Wash fluid of the previous examples must be heated from 28 to $75{ }^{\circ} \mathrm{C}$ with allowable pressure drop for both streams 0.1 bar. The best option for this case is one pass PHE with $29 \mathrm{M} 6 \mathrm{M}$ L-plates $\left(F_{\mathrm{PHE}}=3.78 \mathrm{~m}^{2}\right)$. The smallest for this process conditions

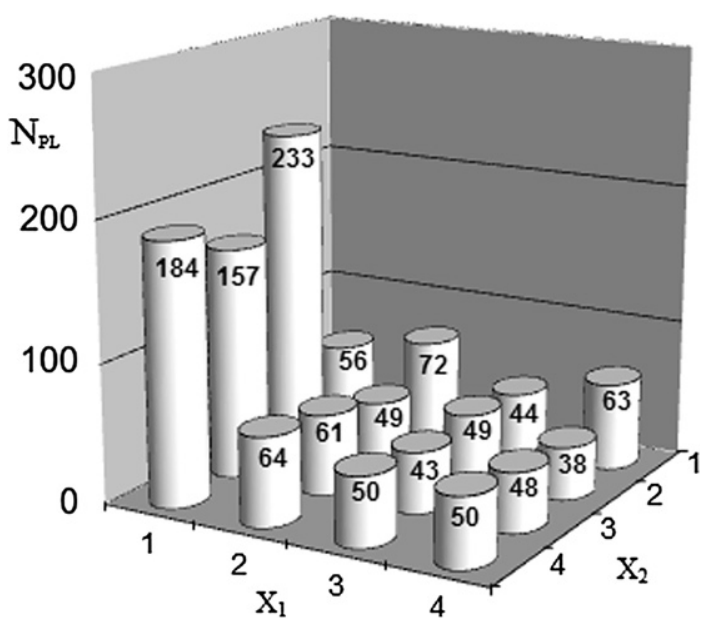

Fig. 6. The influence of passes arrangement on total number of M6M plates in PHE which satisfy the process conditions of Example 1a.
PHE from M6 plates has $43 \mathrm{~L}$-plates and heat transfer area bigger on $63 \%\left(F_{\mathrm{PHE}}=6.15 \mathrm{~m}^{2}\right)$ and margin on heat transfer load $M_{Q}=80 \%$. It shows that, for different process conditions, the plates with different geometrical characteristics are required to satisfy those conditions in a best way. It is urging the leading PHE manufacturers to produce a wide range of plates that can satisfy any process requirements. However, counting for the cost of tools to manufacture new plate type, this way is rather expensive. On the other hand, the process design engineer can optimize process conditions, like allowable pressure drops and temperature program, accounting for characteristics of available types of plates. The data of one representative set of plates, presented in this paper, can facilitate such approach.

\subsection{Case study 2}

This example is that which has been presented by Wang and Sunden [10] (Example 1). It is required to cool $40 \mathrm{~kg} / \mathrm{s}$ of hot water with the initial temperature $70{ }^{\circ} \mathrm{C}$ down to $40{ }^{\circ} \mathrm{C}$. The flow rate of incoming cooling water is $30 \mathrm{~kg} / \mathrm{s}$, with a temperature of $30^{\circ} \mathrm{C}$.

The allowable pressure drop on the hot side, $\Delta P_{1}$, is $40 \mathrm{kPa}$, on the hot side $60 \mathrm{kPa}$. The results of the calculations are presented in Table 4 and on diagram in Fig. 7. In the first five cases (rows in Table 4) the calculations are made for clean plates.

The minimal heat transfer surface area is achieved with the combination of $\mathrm{H}$ and mixed channels - case \#1. Here the allowable pressure drop on hot side is completely used and the heat load is exactly equal to the specified (the margin $M_{Q}$ equal to zero). The option with identical mixed channels (case \#3) has on $5 \%$ bigger area and margin of $1 \%$.

The comparison on diagram in Fig. 7 shows, that for the PHE with identical plates the surface area is much larger. With $\mathrm{H}$ plates (case \#2) it is 73\% larger, but at considerable (68\%) margin. With $\mathrm{L}$ plates (case \#4) the surface area is larger by $150 \%$ with no margin for heat load. The pressure drop is much lower than allowable in

Table 4

Calculations results for Case Study 2 (two M10B PHEs installed in parallel).

\begin{tabular}{cllcllll}
\hline$\#$ & $\begin{array}{l}\text { Total area, } \\
\mathrm{m}^{2}\end{array}$ & Grouping & $\begin{array}{l}\Delta \mathrm{P}_{1}, \\
\mathrm{kPa}\end{array}$ & $\begin{array}{l}\Delta \mathrm{P}_{2}, \\
\mathrm{kPa}\end{array}$ & $\begin{array}{l}R_{f} \times 10^{4}, \\
\mathrm{~m}^{2} \mathrm{~K} / \mathrm{W}\end{array}$ & $M_{\mathrm{Q}} \%$ & $F / F_{\min }$ \\
\hline 1 & 36.96 & $\begin{array}{l}(3 \mathrm{H}+35 \mathrm{M}) / \\
(3 \mathrm{H}+35 \mathrm{M})\end{array}$ & 39 & 26 & 0 & 0 & 1 \\
2 & 63.92 & $64 \mathrm{H} / 64 \mathrm{H}$ & 40 & 21 & 0 & 68 & 1.73 \\
3 & 38.88 & $40 \mathrm{M} / 40 \mathrm{M}$ & 38 & 25 & 0 & 1 & 1.05 \\
4 & 91.68 & $95 \mathrm{~L} / 95 \mathrm{~L}$ & 14 & 8 & 0 & 0 & 2.50 \\
5 & 83.04 & $2 \times 43 \mathrm{~L} / 2 \times 43 \mathrm{~L}$ & 40 & 24 & 0 & 62 & 2.25 \\
6 & 59.04 & $(57 \mathrm{H}+4 \mathrm{M}) /$ & 40 & 23 & $1.0^{\mathrm{a}}$ & 56 & 1.60 \\
7 & 41.76 & $(57 \mathrm{H}+4 \mathrm{M})$ & & & & & \\
& & $(15 \mathrm{H}+28 \mathrm{M}) /$ & 40 & 27 & 0.18 & $10^{\mathrm{a}}$ & 1.13 \\
8 & 46.56 & $(15 \mathrm{H}+28 \mathrm{M})$ & & & & & \\
& & $(26 \mathrm{H}+22 \mathrm{M}) /$ & 40 & 26 & 0.37 & $20^{\mathrm{a}}$ & 1.26 \\
\hline
\end{tabular}

\footnotetext{
a This value is specified at calculation conditions.
} 


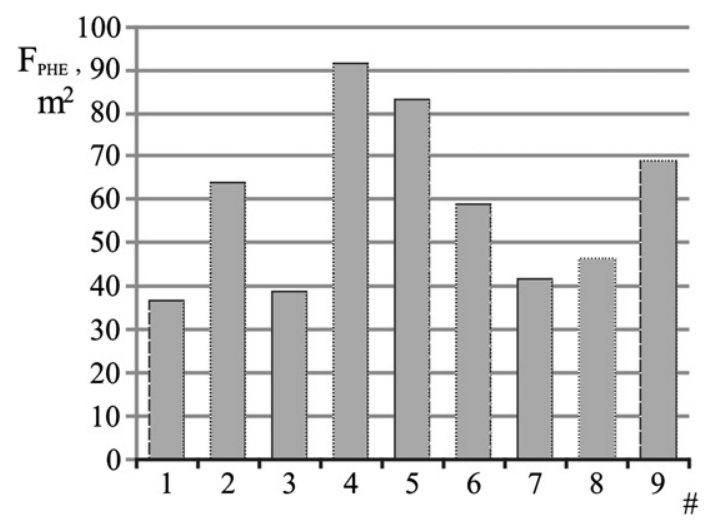

Fig. 7. Comparison of calculated at Case Study 2 heat transfer areas: $1-$ plates $\mathrm{H}+\mathrm{L} ; 2$ - plates $\mathrm{H} ; 3$ - equal numbers of plates $\mathrm{H}$ and $\mathrm{L}$ (M channels only); 4 - plates $\mathrm{L}$ (one pass); 5 - plates $\mathrm{L}$ (two passes); $6-R_{f}=0.0001 \mathrm{~W} /\left(\mathrm{m}^{2} \mathrm{~K}\right), M_{Q}=56 \%$; $7-\mathrm{R}_{\mathrm{f}}=0.000018 \mathrm{~W} /\left(\mathrm{m}^{2} \mathrm{~K}\right), M_{Q}=10 \% ; 8-R_{f}=0.000036 \mathrm{~W} /\left(\mathrm{m}^{2} \mathrm{~K}\right), M_{Q}=20 \%$; 9 - from Wang and Sunden [10].

this case (see Table 4). The increase in the number of passes for L plates (case \#5) also produces a larger surface area (125\%), but the pressure drop is utilized and the margin is $62 \%$.

In the example given by Wang and Sunden [10] the fouling thermal resistance equal to $0.5 \times 10^{-4} \mathrm{~m}^{2} \mathrm{~K} / \mathrm{W}$ was taken for both sides (compare with data for PHEs on fouling reported by Wang, Sunden and Manglik [6], this value is the biggest one). Using analytical approach to solution and proposed by Martin [34] theoretical estimation for parameters in correlations for friction factors and film heat transfer coefficients, Wang and Sunden [10] obtained optimal PHE heat transfer area equal to $68.8 \mathrm{~m}^{2}$. It is represented on diagram in Fig. 7 as case \#9.

The total $R_{f}=1 \times 10^{-4} \mathrm{~m}^{2} \mathrm{~K} / \mathrm{W}$ was taken for our calculations in case \#6. Compare with clean conditions in case \#1, this leads to $60 \%$ increase in surface area, up to $59.04 \mathrm{~m}^{2}$. It is also results in a decrease of flow velocities in the channels, as their number in case \#6 also increased by $60 \%$. In cases \#7 and \#8 (see Table 4 ) the calculations were made with specification of margins 10 and $20 \%$ to overall heat transfer coefficient. The increase of surface area is 13 and $26 \%$, respectively. The corresponding calculated values of $R_{f}$ much lower and for margin $20 \%$ very close to those reported in book [6] for towns water.

All cases, presented by rows in Table 4 and illustrated by diagram in Fig. 7, correspond to local optimal arrangements of plates and passes, which are satisfying the process conditions at different additional constraints. At least one of conditions for two pressure drops (26), (27) or heat load (25) is satisfied as equality in such cases. The PHE with bigger number of plates, than presented in Table 1, will also satisfy process, but with margins on all three parameters. Beside the increased cost of such PHE, it leads to lower streams velocities in channels and thus increases fouling tendency. For cases from \#2 to \#5 the constraint on plate or channel type is imposed. One can see that there only one process condition is satisfied as equality. In case \#1 both $\mathrm{H}$ - and L-plates are used and two conditions (for $\Delta P_{1}$ and $Q$ ) are satisfied exactly. It gives the economy in heat transfer area $73 \%$ compare to use of only H-plates and $125 \%$ if only L-plates are used.

In the three of presented in Fig. 7 cases (\#6, \#7 and \#8) the constraints on fouling thermal resistance (case \#6) and heat load margin are introduced. These additional constraints lead to increase of PHE heat transfer area. But even at highest margin $M_{Q}=56 \%$ (case \#6) PHE area is smaller than that would be needed in PHE assembled from plates of one type ( $\mathrm{H}$ in case \#2 or $\mathrm{L}$ in cases \#4 and \#5). As shown by Gogenko et al. [35], the excessive allowance for fouling in PHEs can lead to increase of fouling in real conditions by lowering the flow velocity and wall sheer stress in channels. This conclusion is justified for particulate solids deposition and scaling fouling mechanisms, which are the main factors of fouling in District Heating networks and cooling water circuits of industrial enterprises.

We have analyzed experience of monitoring and servicing of more than 2000 Alfa Laval PHEs installed by AO Sodrgestvo-T engineering company in a last 16 years at District Heating (DH) systems of Ukraine. $90 \%$ of these PHEs were calculated with zero heat load margin $\left(M_{Q}=0\right)$, others with $M_{Q}=10 \%$ (on special requests). Most of PHEs (75\%) maintains the designed parameters, and not need to be cleaned, from the time of start up. Some, especially those for tap hot water heating, are cleaned by washing with chemicals during scheduled maintenance, but not more frequently than once a year. It depends on quality of DH water and fresh tap water for heating. The mechanical cleaning with disassembling plate-and-frame PHE was required only as exception after re-piping of DH network or its not proper maintenance.

On the above grounds we can recommend, for the conditions of case study considered, the solution with $M_{Q}=0$ (case \#1 in Table 4) as optimal. In other cases of application at the industry, the fouling tendencies of process stream and quality of cooling media must be considered. The value of heat load margin $M_{Q}$ or $R_{f}$ should be specified based on previous experience of heat exchangers fouling in such conditions. In some cases it can constitute the complicated problem, the solution of which is out of the scope of the present study. However, as general rule, when severe fouling tendencies are not expected, heat load margin $M_{Q}=10 \%$ can be recommended, or for heavier fouling duties $M_{Q}=20 \%$. As one can see from Table 4, it gives the surplus in PHE heat transfer area, that is made from $\mathrm{H}$-plates, which corrugation produce higher level of turbulence and thus decrease fouling tendency of the stream.

As one can see from Table 4, in all cases with mixed grouping of channels the specified values of allowable pressure drop for one stream (hot in our example) are satisfied exactly, as is the condition for the heat load (when margin is specified, then with margin). It means that by using the mixed grouping of plates with different corrugation pattern, we can change the thermal and hydraulic characteristics of a plate pack in a way close to continues one. The level of discreteness is equal to one plate in a pack. It allows us to satisfy specified conditions very close to equality.

The optimization solution algorithm is based on two considerations. The first one is that for a given plate type and passes configuration the local optimum for heat transfer area, as an objective function, situated in a place where the constraints on pressure drops are fulfilled closer to equality. The second consideration is that smaller number of passes is preferable. For the given plate type the calculations are starting from one pass arrangement and passes numbers are increased, while objective function is lowering. When it becomes to grow, the local optimum for the given plate type is found by comparison of all results for different passes configurations. These calculations are made for all available types of plates, which satisfy the constraints on PHE construction (28)-(30). Comparison of all obtained local optimums gives a global one. The number of available plate types is limited, and the solution takes time not more than a second or two on PC with Intel processor of $2.0 \mathrm{MHz}$ frequency. As iteration procedures are not used, there are no problems of convergence. Some increase in computing time can happen for multi-pass arrangements, on a stage of solving the system of linear algebraic equations (7) of a big size. In the developed computer program, to exclude unfeasible solutions, the maximal number of passes for one stream is limited to 10 and the product of two passes numbers to $X_{1} \times X_{2} \leq 50$. 


\section{Conclusions}

Design and optimization method for the PHE is presented which provides better solutions than existing published methods. It is based on mathematical model accounting for the main features determining PHE thermal and hydraulic performance. To obtain solution with minimal heat transfer area for different process conditions is possible only for a wide enough range of plate types and sizes. The optimization variables are: type of plate, the numbers of passes for heat exchanging streams, the relative numbers of plates with different corrugation patterns in one PHE. The proposed procedure of model parameters identification enables to determine their values for commercial plates. It is made for a set of plates with different geometrical characteristics and forms of corrugations.

The examples of calculation results for two case studies show the possibility with such method to obtain optimal solutions with exact satisfaction of constraints for total heat load and pressure drop of one stream. It gives the considerable reduction in heat transfer surface area of PHE. However, for specific plate type it is possible only in the limited range of process conditions. It requires in search of optimal solution to use types of plates with the similar heat transfer area, but other spacing. Another approach is the optimization of a whole heat recuperation system, and process conditions for specific heat exchangers, with accounting for available types of plates and a full utilization of pressure drops for both streams. Special attention should be paid to exact accounting of fouling thermal resistance on plate surfaces. This phenomenon, as also methods of process optimization with accounting for intrinsic features of PHEs require further developments, which can utilize all the possibilities available with the use of this highly efficient heat transfer equipment.

The presented method and parameters in mathematical model can be used for statistics when generalizing the correlations for PHEs thermal and hydraulic performance, for modelling of PHEs when making multiple calculations for heat exchangers network design and also for education of engineers specializing on heat transfer equipment selection. On a final stage of ordering the PHE the calculations should be made by PHE manufacturers, which are permanently developing the design procedures and performance of produced equipment, and most probably can offer PHE with even better performance.

\section{Acknowledgements}

The financial support of EC Project FP7-SME-2010-1-262205INTHEAT is sincerely acknowledged.

\section{References}

[1] Klemeš J, Friedler F, Bulatov I, Varbanov P. Sustainability in the process industry. Integration and optimization. New York, USA: The McGraw-Hill Companies, Inc.; 2010.

[2] Perry S, Klemeš J, Bulatov I. Integrating waste and renewable energy to reduce the carbon footprint of locally integrated energy sectors. Energy 2008;33: 1489-97.

[3] Fodor Z, Varbanov P, Klemeš J. Total site targeting accounting for individual process heat transfer characteristics. Chemical Engineering Transactions 2010;21:49-54. doi:10:3303/CET1021025.

[4] Kapustenko PO, Ulyev LM, Boldyryev SA, Garev AO. Integration of a heat pump into the heat supply system of a cheese production plant. Energy 2008;33: 882-9.

[5] Hesselgreaves JE. Compact heat exchangers. Selection, design and operation. Oxford, UK: Elsevier; 2001.

[6] Wang L, Sunden B, Manglik RM. PHEs. Design, applications and performance. Southhampton, UK: WIT Press; 2007.

[7] Shah RK, Seculić DP. Fundamentals of heat exchanger design. New York, USA: Wiley and Sons; 2003.
[8] Tovazshnyansky LL, Kapustenko PO, Khavin GL, Arsenyeva OP. PHEs in industry. Kharkiv, Ukraine: NTU KhPI; 2004 [in Russian].

[9] Focke WW. Selecting optimum plate heat exchanger surface patterns. Journal of Heat Transfer 1986;108(1):153-60.

[10] Wang L, Sunden B. Optimal design of PHEs with and without pressure drop specifications. Applied Thermal Engineering 2003;23:295-311.

[11] Picon-Nunez M, Polley GT, Jantes-Jaramillo D. Alternative design approach for plate and frame heat exchangers using parameter plots. Heat Transfer Engineering 2010;31(9):742-9.

[12] Mehrabian MA. Construction, performance, and thermal design of plate heat exchangers. Proceedings of the Institution of Mechanical Engineers, Part E: Journal of Process Mechanical Engineering 2009;223(3):123-31.

[13] Wright AD, Heggs PJ. Rating calculation for plate heat exchanger effectiveness and pressure drop using existing performance data. Transactions of IChemE 2002;80(Part A, April):309-12.

[14] Kanaris AG, Mouza AA, Paras SV. Optimal design of a plate heat exchanger with undulated surfaces. International Journal of Thermal Sciences 2009;48: 1184-95.

[15] Marriott J. Performance of an Alfaflex plate heat exchanger. Chemical Engineering Progress 1977;73(2):73-8.

[16] Cocks AM. Plate heat exchanger design by computer. Chemical Engineer (London) 1969;228:193-8.

[17] Kumar H. Plate heat exchanger: construction and design. Institution of Chemical Engineers Symposium Series 1994;86:1275-88.

[18] Zinger NM, Barmina LS, Taradai AM. Design of plate heat exchangers for heat supply systems. Thermal Engineering (English Translation of Teploenergetika) 1988;35(3):141-5.

[19] Pignotti A, Shah RK. Effectiveness-number of transfer units relationships for heat exchangers complex flow arrangements. International Journal of Heat and Mass Transfer 1992;35(5):1275-91.

[20] Pignotti A, Tamborenia PI. Thermal effectiveness of multipass plate exchangers. International Journal of Heat and Mass Transfer 1988;31(10): 1983-91.

[21] Kandlikar SG, Shah RK. Asymptotic effectiveness-NTU formulas for multipass plate heat exchangers. Transactions of the ASME 1989;111(5):314-21.

[22] Tovazhnyansky LL, Kapustenko PA, Pavlenko VF, Derevyanchenko IB, Babak TG, Lupyr VF. The optimum design of multi-pass dismountable PHEs. Chemical and Petroleum Engineering 1992;28(6):354-9.

[23] Arsenyeva O, Tovazhnyansky L, Kapustenko P, Khavin G. Mathematical modelling and optimal design of plate-and-frame heat exchangers. Chemical Engineering Transactions 2009;18:791-6. doi:10.3303/CET0918129.

[24] Rao BP, Kumar PK, Das SK. Effect of flow distribution to the channels on the thermal performance of a plate heat exchanger. Chemical Engineering and Processing 2002;41:49-58.

[25] Bassiouny MK, Martin H. Flow distribution and pressure drop in plate heat exchangers - I. Chemical Engineering Science 1984;39(4):693-700.

[26] Kukulka DJ, Devgun M. Fluid temperature and velocity effect on fouling. Applied Thermal Engineering 2007;27:2732-44.

[27] Heggs PJ, Scheidat HJ. Thermal performance of plate heat exchangers with flow maldistribution. In: Shah RK, Rudy TM, Robertson JM, Hostetler KM, editors. Compact heat exchangers for power and process industries, vol. 201. New York: ASME; 1992. p. 87-93.

[28] Shah RK, Focke WW. Plate heat exchangers and their design theory. In: Shah RK, Subbarao EC, Mashelkar RA, editors. Heat transfer equipment design. Washington DC, USA: Hemisphere; 1988. p. 227-54.

[29] Shah RK, Wanniarachchi AS. Plate heat exchanger design theory. In: Buchlin J-M, editor. Industrial heat exchangers. Lecture Series, vol. 4. Belgium: von Karman Institute for Fluid Dynamics; 1991.

[30] Georgiadis MC, Macchietto S. Dynamic modelling and simulation of plate heat exchangers under milk fouling. Chemical Engineering Science 2000;55: 1605-19.

[31] Alfa Laval. Gasketed industrial range PHE. Documentation. alfalaval.com/ solution-finder/products/gasketed-industrial-range-phe [accessed 02.01.11].

[32] Energo Soft. CAS 200. energosoft.info/soft_teplotex_21_30.html accessed [02.01.20].

[33] Kapustenko P, Boldyryev S, Arsenyeva O, Khavin G. The use of plate heat exchangers to improve energy efficiency in phosphoric acid production. Journal of Cleaner Production 2009;17:951-8.

[34] Martin $\mathrm{H}$. Theoretical approach to predict the performance of chevron-type plate heat exchangers. Chemical Engineering and Processing 1996;35:301-10.

[35] Gogenko AL, Anipko OB, Arsenyeva OP, Kapustenko PO. Accounting for fouling in plate heat exchanger design. Chemical Engineering Transactions 2007;12: 207-13.

\section{Nomenclature}

b: channel width, $\mathrm{m}$

c: specific heat capacity of the stream, $\mathrm{J} /(\mathrm{kg} \mathrm{K})$

$d_{e}$ : equivalent diameter, $\mathrm{m}$

$F$ : heat transfer area, $\mathrm{m}^{2}$

$f$ : cross section area of inter-plate channel, $\mathrm{m}^{2}$

$\mathrm{G}$ : mass flow rate, $\mathrm{kg} / \mathrm{s}$

$\mathrm{g}$ : the flow rate of the stream through the channel, $\mathrm{kg} / \mathrm{s}$

$L_{p}$ : effective plate length, $\mathrm{m}$ 
$M_{Q}=100 \cdot\left(Q-Q^{0}\right) / Q^{0}$ : heat load margin, \%

$n_{b}$ : the total number of blocks

$n_{x}, n_{y}$ : the numbers of $x$ and $y$ channels, respectively

$N_{p l}$ : number of heat transfer plates

$N T U$ : the number of heat transfer units

$\Delta p$ : pressure drop, $\mathrm{Pa}$

$Q$ : heat load, $\mathrm{W}$

$R$ : the ratio of flow heat capacities of streams

$R_{f}$ : the fouling thermal resistances for streams, $\mathrm{m}^{2} \mathrm{~K} / \mathrm{W}$

$T_{p l}$ : plate type

$\delta t$ : the change of temperature, ${ }^{\circ} \mathrm{C}$

$\Delta t_{i}$ : the temperature difference of streams entering block $i$

$t_{11}, t_{12}$ : hot stream inlet and outlet temperatures, ${ }^{\circ} \mathrm{C}$

$t_{21}, t_{22}$ : cold stream inlet and outlet temperatures, ${ }^{\circ} \mathrm{C}$

$U$ : overall heat transfer coefficient, $\mathrm{W} /\left(\mathrm{m}^{2} \mathrm{~K}\right)$

$w$ : stream velocity, $\mathrm{m} / \mathrm{s}$

$X:$ number of passes

Pr: Prandtl number

$\mathrm{Nu}$ : Nusselt number

L: low duty

$H$ : high duty $h$ : film heat transfer coefficient, $\mathrm{W} /\left(\mathrm{m}^{2} \mathrm{~K}\right)$

$\delta_{w}$ : the wall thickness, $\mathrm{m}$

$\lambda$ : heat conductivity, $\mathrm{W} /(\mathrm{m} \mathrm{K})$

$\mu$ : the dynamic viscosity, $\mathrm{cP}$

$\delta$ : inter-plate gap, $\mathrm{m}$

$\rho$ : stream density, $\mathrm{kg} / \mathrm{m}^{3}$

$\zeta$ : friction factor

$\epsilon$ : heat exchange effectiveness

Subscripts

1: hot stream

2: cold stream

$b$ : block

$i$ : the number of block

$w$ : wall

$p-c$ : in ports and collector part

pl: plate

PHE: plate heat exchanger

Superscripts

0 : value required by the process conditions 